\title{
INCREASED ALDOSTERONE SECRETION FOLLOWING ACUTE CONSTRICTION OF THE INFERIOR VENA CAVA ${ }^{1}$
}

\author{
BY JAMES O. DAVIS, BERNARD KLIMAN, NICHOLAS A. YANKOPOULOS, AND \\ RALPH E. PETERSON WITH THE SURGICAL ASSISTANCE OF \\ ALFRED CASPER
}

(From the Section on Experimental Cardiovascular Disease, Laboratory of Kidney and Electrolyte Metabolism, National Heart Institute, and the Institute of Arthritis and Metabolic Disease, Bethesda, Md.)

(Submitted for publication June 6, 1958; accepted August 25, 1958)

Aldosterone secretion (1) and aldosterone excretion in urine (2) are markedly elevated in dogs with chronic right heart failure and in dogs with chronic ascites secondary to thoracic caval constriction. It was suggested that the adrenal cortex is stimulated to secrete aldosterone by factors resulting from a high venous pressure and the consequent loss of fluid and electrolytes from the blood stream. The precise nature of these factors remains to be defined.

The purpose of the present study was threefold: 1) to determine the effects of acute caval constriction on aldosterone secretion in an attempt to develop an acute experimental preparation for evaluation of factors influencing aldosterone secretion; 2) to evaluate the effect of changes in vascular volume on aldosterone output; and 3) to apply a radioisotope derivative technique developed by two of us (B. K. and R. E. P.) for the determination of aldosterone and corticosterone in $2 \mathrm{ml}$. samples of adrenal vein plasma.

\section{METHODS}

The material for this study consisted of 11 mongrel dogs. Three types of experiments were conducted. In Experiment I (four dogs), the effects of acute constriction of the thoracic inferior vena cava were studied. In Experiment II (four dogs), the inferior vena cava was constricted immediately above the entrance of the adrenolumbar veins. Experiment III (three dogs) was performed to ascertain the influence of thoracic caval constriction while an intravenous infusion of dextran was administered to maintain or to increase plasma volume. Dextran (Expandex ${ }^{\circledR}$ ) was injected as a 6 per cent solution in isotonic sodium and potassium chloride; the osmolality of the solution was $290 \mathrm{mOsm}$.

The design of the study consisted of observations during a control period of one hour and for three to four

1 Reported at the spring meeting (1958) of the American Physiological Society. hours following caval constriction. Three series of control observations were made at 30 minute intervals. The experimental alteration, which consisted of caval constriction alone or with an accompanying dextran infusion, was then introduced and six to eight groups of determinations were made at similar intervals during the experimental period.

In all experiments a nylon ligature was placed around the inferior vena cava before control observations were made. The ligature was extended through a silver cannula to the outside of the chest wall so that constriction could be accomplished later without opening the chest between the control and experimental periods. The animals received 100 per cent oxygen through an endotracheal tube attached to a pneophore at a pressure of 15 $\mathrm{cm}$. water. Adrenal vein blood was collected and measurements of adrenal blood flow were made by a technique described previously (1). Ten $\mathrm{ml}$. of adrenal vein blood and 10 to $14 \mathrm{ml}$. of peripheral blood were removed for each group of analyses; donor blood was given immediately to replace the blood withdrawn. Arterial and venous pressures were measured in the abdominal aorta and inferior vena cava, respectively, by continuous recording with Statham strain gages and a Sanborn recording system. Venous pressure was referred to a level $6 \mathrm{~cm}$. above the table surface. Dextran was given by means of a constant infusion pump into an external jugular vein.

Aldosterone and corticosterone were determined in 2 ml. samples of adrenal vein plasma by a double isotope derivative technique (3). Plasma was extracted with methylene chloride and the extract dried and acetylated with a 10 per cent solution of tritium-labeled acetic anhydride in benzene. Measured amounts of authentic aldosterone diacetate- $\mathrm{C}^{14}$ and corticosterone monoacetate- $\mathrm{C}^{14}$ were added and the double labeled steroids separated and purified by paper chromatography. After two chromatographies, the samples were treated with 0.5 per cent chromic acid in glacial acetic acid. A final chromatography was used to separate the aldosterone and corticosterone acetates from other labeled materials. The tritium and carbon-14 content of the purified steroids was determined with a liquid scintillation spectrometer. The ratio of tritium to carbon-14 approached a constant value after the third chromatography. The quantities of aldosterone and corticosterone present in the sample of plasma 
were calculated from the amount of carbon-14 lost during chromatography, the yield of tritium radioactivity and the specific activity of the tritium-labeled acetic anhydride. Recoveries for aldosterone yielded values of 95 to 100 per cent. Porter-Silber reacting chromagens in adrenal vein plasma were measured by a modification (4) of the method of Silber and Porter (5). Studies (6) have demonstrated that 60 to 70 per cent of these chromagens is hydrocortisone and 10 to 20 per cent is 11 desoxyhydrocortisone (Compound $\mathrm{S}$ ). The rates of secretion of adrenal steroids were calculated from the concentrations in adrenal vein plasma ${ }^{2}$ and the rate of adrenal plasma flow. Preliminary data on equilibration of aldosterone with whole dog blood for one hr. at $37^{\circ} \mathrm{C}$. showed that 45 per cent of the aldosterone was recovered from the red blood cells. From this value the concentration of aldosterone in whole blood can be calculated from the formula : $\mu \mathrm{g}$. per cent of aldosterone in whole blood $=\mu \mathrm{g}$. per cent of aldosterone in plasma $(1-$ hematocrit + hematocrit $\times 0.818$ ), where 0.818 is the ratio

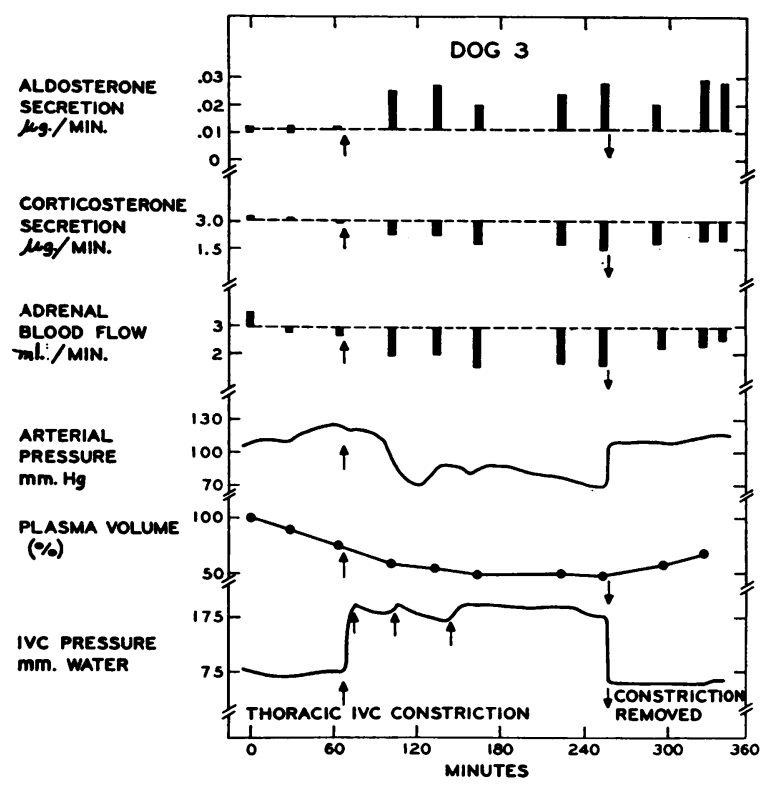

Fig. 1. Effects of Acute Constriction of the Thoracic Inferior Vena Cava (IVC) on Aldosterone and Corticosterone Secretion in Adrenal Vein Plasma

Associated measurements of adrenal blood flow, arterial pressure, plasma volume and IVC pressure are presented. Arrows pointing upward indicate tightening of constricting ligature whereas release of ligature is represented by arrows pointing downward. The dotted lines show the average values for three control determinations.

2 This calculation neglects the very low concentration of aldosterone in peripheral plasma which measurements show to be less than 1 per cent of that in adrenal vein plasma. of aldosterone in red blood cells to that in plasma. $\mathrm{He}-$ moglobin was measured as oxyhemoglobin (7). Changes in plasma volume were calculated from the formula:

$$
\frac{\mathrm{PV}_{2}}{\mathrm{PV}_{1}}=\frac{\mathrm{Hgb}_{1}}{\mathrm{Hgb}_{2}} \times \frac{1-\mathrm{Hct}_{2}}{1-\mathrm{Hct}_{1}}
$$

Plasma sodium and potassium were determined by flame photometry. Total plasma osmolality was measured with a freezing point apparatus designed by Bowman, Trantham and Caulfield (8).

\section{RESULTS}

Experiment I. Effects of acute constriction of the thoracic inferior vena cava (Dogs 1 through 4)

The secretion of aldosterone in adrenal vein plasma increased within 30 minutes and reached levels two- to fourfold greater than the average control rates of 0.008 to $0.024 \mu \mathrm{g}$. per minute (Figures 1 and 2). In contrast, corticosterone (see Figure 1) and Porter-Silber reacting steroid output decreased in three of the four dogs. This decline in steroid secretion was associated with a decrease in adrenal blood flow. Release of the ligature after approximately three hours failed to influence aldosterone secretion; adrenal blood flow, corticosterone secretion, and Porter-Silber steroid output remained unchanged or increased toward the control values.

The increase in aldosterone secretion was associated with an elevation in inferior vena caval pressure of 8 to $13 \mathrm{~cm}$. of water, a reduction in arterial pressure of 10 to $55 \mathrm{~mm}$. $\mathrm{Hg}$ and a decrease in plasma volume of 36 to 65 per cent. No consistent changes in the concentrations of plasma sodium or potassium were observed and plasma osmolality was not detectably altered. Removal of the constriction was followed immediately by complete or nearly complete restoration of cardiovascular hemodynamic function but plasma volume increased only slightly (4 to 20 per cent) during a recovery period of one and one-half hours.

\section{Experiment II. Effects of acute constriction of the abdominal inferior vena cava above the ad- renolumbar veins (Dogs 5 through 8)}

Constriction of the abdominal inferior vena cava resulted in increased aldosterone output in two of the four animals (Dogs 6 and 7). The response occurred (see Figure 3 ) only in the 
presence of marked caval constriction and in association with large sustained increments (greater than $14 \mathrm{~cm}$. of water) in venous pressure. In Dog 6, the initial constriction with a resultant elevation in venous pressure of 16 to $20 \mathrm{~cm}$. of water failed to stimulate aldosterone secretion, but, later in the experiment, further constriction of the vena cava with an additional increment in venous pressure of 4 to $6 \mathrm{~cm}$. of water was accompanied by a progressive elevation in aldosterone secretion from 0.05 to $0.16 \mu \mathrm{g}$. per minute. When the rise in venous pressure after abdominal caval constriction was not sustained at a high level, aldosterone secretion remained unchanged or decreased (see Figure 4). These findings are in contrast to the results observed following thoracic caval constriction in which aldosterone output was consistently elevated with a rise in venous pressure of less than $13 \mathrm{~cm}$. water. The changes in corticosterone and Porter-Silber re-

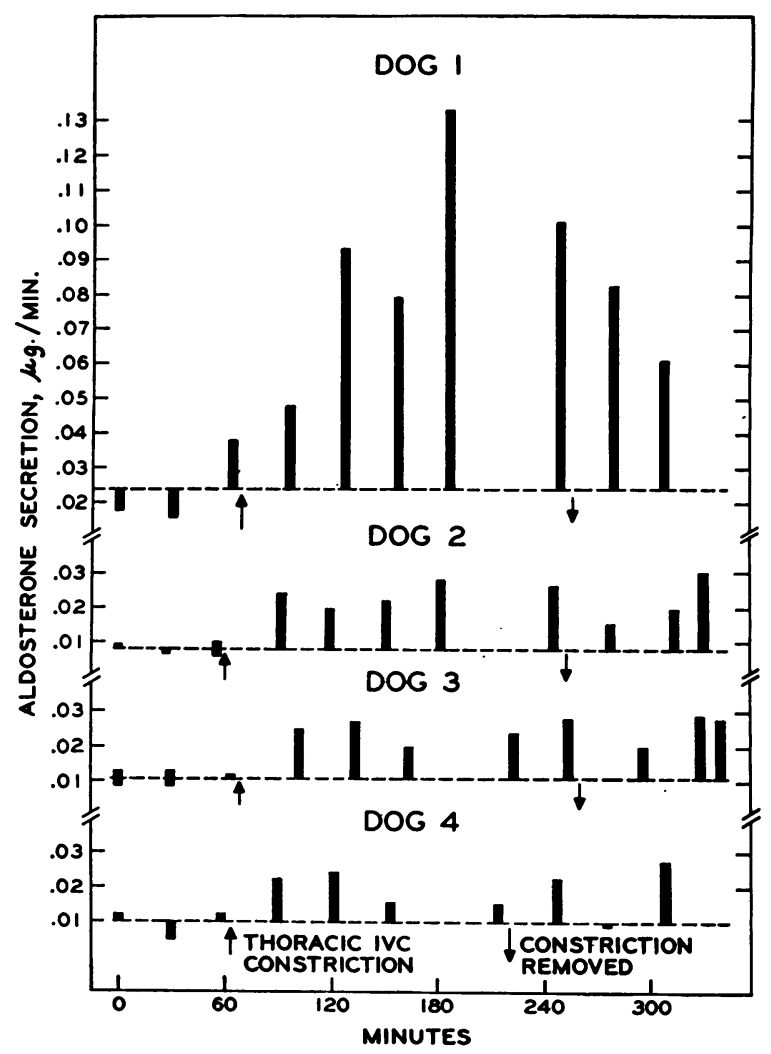

Fig. 2. Response of Aldosterone Secretion to Acute Thoracic Inferior Vena Cava Constriction See Figure 1 for description of symbols.

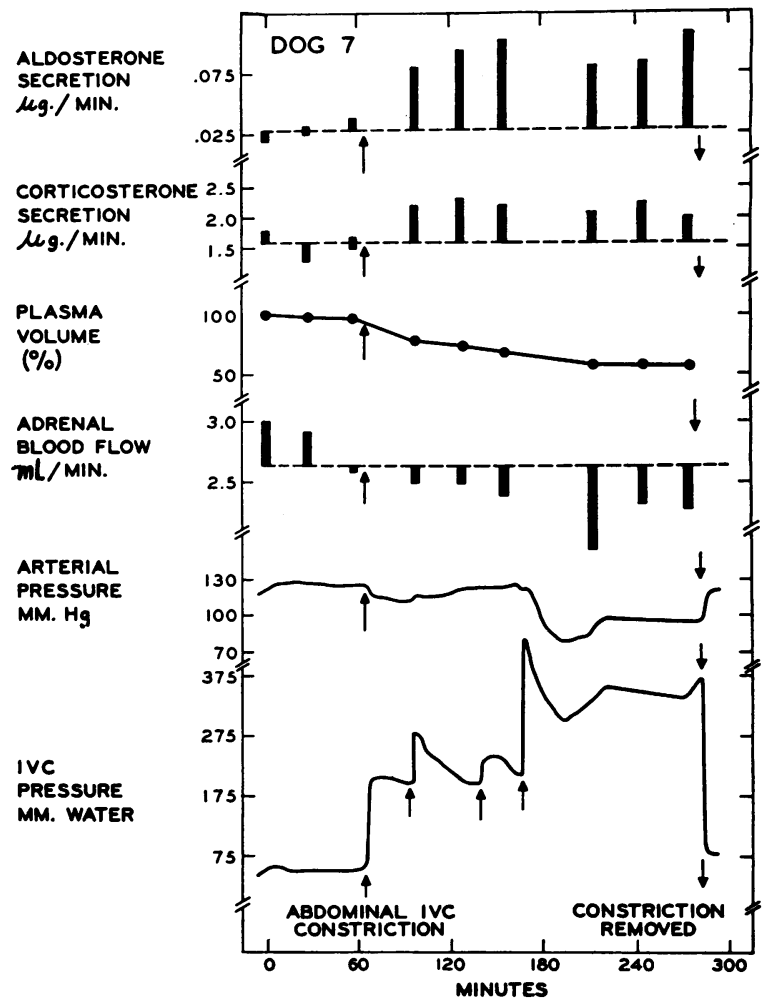

Fig. 3. Increased Aldosterone and Corticosterone Secretion Following Acute Constriction of the Abdominal InfERIor Vena Cava

See Figure 1 for description of symbols.

acting steroid secretion were slight and variable, except in Dog 7 in which a definite elevation in both corticosterone and Porter-Silber reacting steroid output accompanied increased aldosterone secretion.

Increased secretion of aldosterone following abdominal caval constriction was apparently not related to a fall in arterial pressure. An elevation in aldosterone output occurred in the presence of an unchanged arterial pressure during the last three periods (Dog 6) and during the first three postconstriction periods in Dog 7 (Figure 3 ). In Dogs 5 (Figure 4) and 8, in which aldosterone output failed to increase, arterial pressure remained unchanged or decreased slightly.

Plasma volume decreased 25, 18 and 44 per cent in Dogs 5, 6 and 7, respectively, but was unchanged in Dog 8. The concentrations of plasma sodium and potassium and total plasma osmolality were not detectably altered. 
Experiment III. The effects of thoracic caval constriction during infusion of dextran (Dogs 9 through 11)

Following constriction of the thoracic inferior vena cava, dextran was given intravenously at a rate estimated by calculation from Experiment I to maintain or to increase plasma volume. In all three dogs, the increase in aldosterone secretion was similar to that observed in Experiment I (see Figure 5). This occurred in spite of increments in plasma volume of 44,80 and 330 per cent. The changes in cardiovascular function were similar in magnitude to those observed in Experiment I; arterial pressure remained unchanged or fell while venous pressure increased. Adrenal blood flow fell progressively throughout the experiment (Dog 9, Figure 5) or fell during the first two hours with a return toward or to the control levels during the last one to two hours of the experiment in the other two animals. No consistent alterations in plasma sodium, potassium or total osmolality were detected.

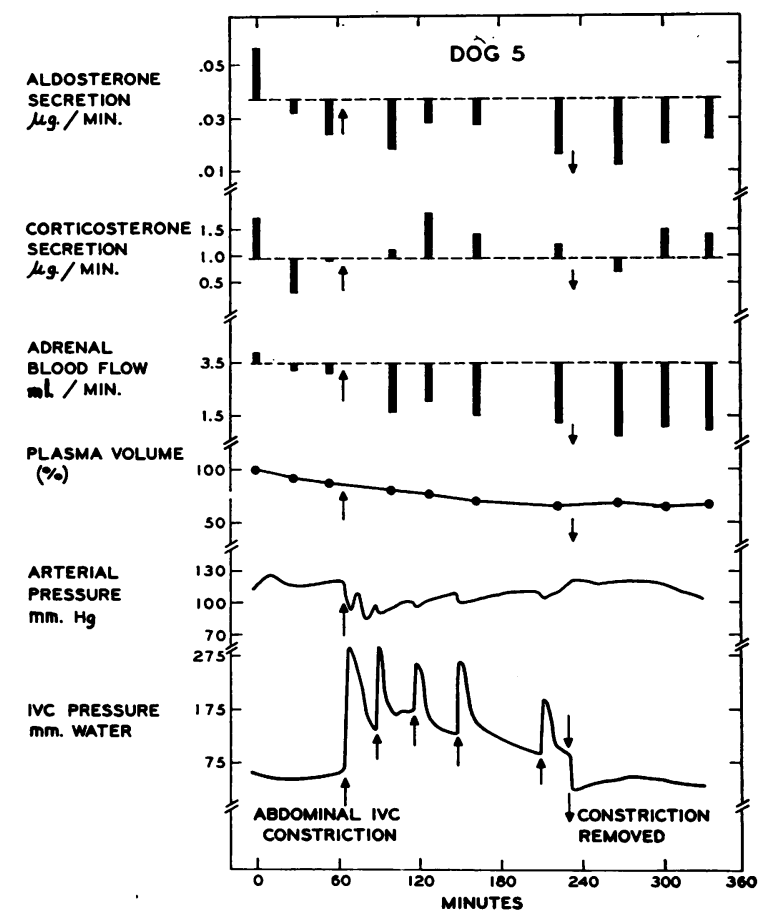

Fig. 4. Failure of Aldosterone Secretion to InCrease Following Acute Abdominal IVC Constriction See Figure 1 for description of symbols.

\section{DISCUSSION}

The present experiments demonstrate that acute constriction of the inferior vena cava resulted in increased aldosterone secretion. The response was consistent following thoracic caval constriction whereas aldosterone secretion increased in only two of the four dogs with abdominal inferior vena cava constriction. In these two animals the elevated venous pressure was sustained at a higher level than in the two dogs not showing a response. The two animals in which aldosterone secretion was unchanged or declined provide control data for the dogs with thoracic inferior vena cava constriction; the results indicate that other factors such as trauma and changes in anesthesia failed to result in increased aldosterone secretion. Failure of aldosterone secretion to decrease after release of the thoracic caval ligature is probably a reflection of the short recovery period, and consequently of inadequate time for aldosterone output to return to the control level.

In has been shown previously (9) that chronic constriction of the abdominal inferior vena cava does not result in increased aldosterone output and sodium retention whereas chronic thoracic caval constriction produces these alterations consistently $(1,2)$. This difference in response apparently is related to the greater ease of filtration of fluid and electrolytes from the liver and hepatic lymphatics of the latter preparation in comparison with that from the congested area in dogs with abdominal caval constriction. Edema or ascites failed to occur after chronic abdominal caval constriction although a higher level of venous pressure was present than observed following thoracic caval constriction. In the absence of or during minimal extravascular loss of fluid and electrolytes, as in Dogs 5 and 8 of the present study, the stimulus may have been inadequate to effect an elevation in aldosterone production.

Increased aldosterone secretion has been reported previously (1) for dogs with chronic heart failure or with chronic ascites secondary to thoracic caval constriction. In recent unpublished studies with the present radioisotope technique for measuring aldosterone, a markedly elevated rate of aldosterone secretion in adrenal vein plasma (mean value of $0.142 \mu \mathrm{g}$. per minute; 
$\mathrm{N}$ equals 8) was observed in dogs with chronic ascites produced by thoracic caval constriction. Increased secretion of aldosterone has also been reported in nephrotic rats with edema or ascites by Singer (10). Histochemical studies of the adrenal cortex from dogs with experimental ascites by Hamilton, Brown and Hague (11) and from dogs with experimental congestive failure by Deane and Barger (12) have provided additional data indicative of increased adrenal cortical activity in the zona glomerulosa. There is, therefore, considerable evidence for increased secretion of aldosterone in experimental states with edema or ascites and, consequently, a satisfactory explanation for the source of the excess circulating hormone which is excreted in urine (2). Nevertheless, evidence to the contrary has been reported by Driscol, Maultsby, Farrell and Berne (13). These workers were unable to detect either increased secretion or increased urinary excretion of aldosterone in dogs with apparent experimental heart failure produced by controlled progressive pulmonic stenosis.

The rapidity of the response in adrenal vein aldosterone output to caval constriction in the present study and to hemorrhage [Farrell, Rosnagle and Rauschkolb (14)] provides evidence that alterations in aldosterone secretion may constitute an important acute homeostatic mechanism. This possibility has been clearly recognized by many investigators. Epstein (15) has recently suggested "the direct adrenal participation in a number of acute renal readjustments, such as the antinatriuresis of quiet standing, of limb congestion, or of hemorrhage." The dog with acute abdominal caval constriction provides an experimental situation comparable to that of quiet standing and of limb congestion in man. Also, the increments in venous pressure observed in the present study were similar to those of Farber, Becker and Eichna (16) following acute caval obstruction in man. These workers were unable to explain the drop in sodium and water excretion on the basis of renal hemodynamic changes alone and they too suggested a hormonal mechanism.

Some question has been raised $(12,13)$ as to the importance of aldosterone in the pathogenesis of edema and ascites. It was suggested that increased aldosterone production might occur late in the course of edema or ascites formation and,

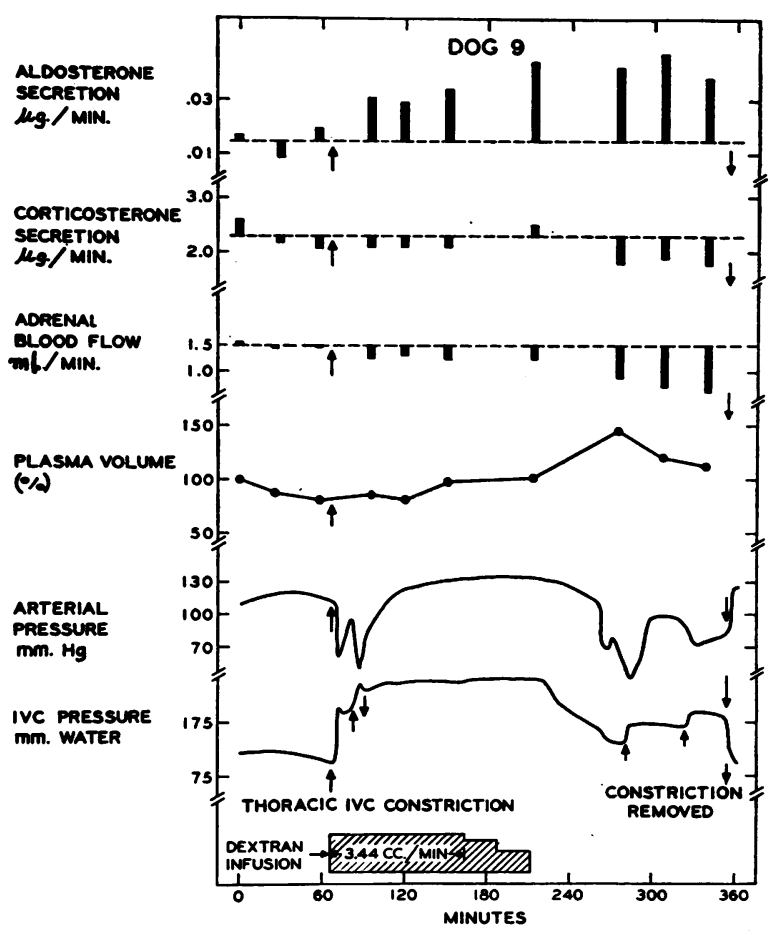

Fig. 5. Increased Aldosterone Secretion Following Thoracic IVC Constriction During Maintained or INCREASED VASCULAR VOLUME

See Figure 1 for description of symbols.

therefore, contribute only as a secondary mechanism. The present data demonstrate the acuteness of the response of the adrenal cortex in the secretion of increased amounts of aldosterone following an alteration in cardiovascular function. Increased aldosterone secretion occurred within 30 minutes following caval constriction. Also, increased excretion of aldosterone in urine has been demonstrated during the first four days following either caval constriction or pulmonic stenosis (17).

The role of aldosterone in the formation of ascites does not appear to be a "permissive" one. In adrenalectomized dogs with caval constriction (18), only $0.5 \mathrm{mg}$. per day of desoxycorticosterone acetate (DCA) was necessary to maintain the animals in sodium balance but 6 to 10 times this amount of DCA was required to effect the degree of sodium retention observed in the presence of the adrenals and endogenous aldosterone. Similarly, it was demonstrated that the degree of sodium retention in dogs with cardiac failure was related to the amount of DCA given (19). It should be emphasized that the effects of desoxy- 
corticosterone and aldosterone on electrolyte excretion by the kidney are qualitatively identical [Liddle, Cornfield, Casper and Bartter (20)]. In addition, observations on urinary aldosterone and sodium excretion in both dog (2) and man by Luetscher and Johnson (21) have demonstrated that an inverse relation between these functions is very frequently present.

Failure of large amounts of DCA to produce chronic sodium retention in both normal $(22)$ and simple adrenalectomized animals (23) may be explained by the necessity of factors other than an excess of circulating sodium-retaining hormone for chronic sodium retention. The importance of a cardiovascular factor which acts in association with aldosterone to promote chronic sodium retention has been emphasized $(1,2,24)$. In dogs with thoracic caval constriction (25) or with experimental heart failure of either the low output (26) or high output (24) type, this factor appears to be elevated venous pressure.

Three lines of evidence support the view that venous hypertension initiates the sequence of events leading to chronic sodium retention in dogs with experimental ascites. First, in dogs with chronic thoracic caval constriction and ascites, venous hypertension below the constriction was usually the only detectable cardiovascular alteration (25). In the majority of these animals, arterial pressure and cardiac output were normal. Second, in dogs with right heart failure secondary to pulmonic stenosis and in dogs with thoracic caval constriction, ascites formed during the first one to four days following the onset of cardiac failure or after caval constriction in the absence of sodium intake (17). Since sodium was not ingested, a positive sodium balance could not occur; ascitic fluid was formed by a shift of electrolytes and water from other body fluids. Therefore, in the dogs with pulmonic stenosis, a full-blown clinical picture of frank congestive heart failure with ascites developed in the absence of a renal factor with its resultant positive sodium balance. Third, an analysis of the functional changes during high output failure secondary to anemia in dogs with pulmonic stenosis (24) showed that an elevation in right atrial pressure was closely associated with sodium retention; cardiac output, glomerular filtration rate and renal plasma flow were elevated in the majority of instances.

It has been repeatedly suggested that the stimulus to increased aldosterone production arises as a result of some unknown factor or factors associated with loss of fluid and electrolytes from the blood stream. Johnson and Conn (27) have referred to the effect of venous pressure as creating a "leak" of salt and water from the circulation with a resultant abnormal redistribution of extracellular fluid. It was reasoned (28) that if the stimulus to increased aldosterone secretion is related to loss of fluid and electrolytes from the vascular bed, prevention or inhibition of this loss should result in decreased aldosterone output and a natriuresis. To inhibit transudation of fluid, a plaster body cast was applied to dogs with thoracic caval constriction and ascites (28); aldosterone output dropped and sodium excretion increased. The data suggest a close association between increased aldosterone secretion and factors associated with fluid and electrolyte loss from the vascular bed.

The precise changes which accompany the acute loss of fluid and electrolytes from the blood stream and stimulate aldosterone production remain obscure. The mechanism does not seem to be effected by increased secretion of adrenocorticotropic hormone (ACTH) since corticosterone output was decreased following acute thoracic caval constriction. The present data do not suggest that under these conditions the increased aldosterone secretion is the result of a decreased vascular volume, proposed by Bartter (29) as the normal stimulus for aldosterone secretion. Intravenous administration of dextran at a rate sufficient to maintain or to increase plasma volume markedly failed to prevent the rise in aldosterone secretion following thoracic caval constriction. Also, Farrell and associates (14) observed an increase in aldosterone secretion following hemorrhage in spite of an elevated plasma volume secondary to infused dextran. Thus, observations on the relation of aldosterone secretion to vascular volume in acute animal experiments agree with the frequent finding of a normal or high blood volume in patients with cardiac decompensation $(30,31)$ and during decompensated hepatic cirrhosis (32). 


\section{SUM MARY}

The effects of acute constriction of the thoracic inferior vena cava (seven dogs) and of the abdominal inferior vena cava above the adrenals (four dogs) on aldosterone, corticosterone and Porter-Silber steroid secretion in adrenal vein plasma were studied. Three of the dogs with thoracic caval constriction received dextran intravenously to maintain or to increase plasma volume. After three control determinations $30 \mathrm{~min}$ utes apart, six to eight measurements were made at similar intervals during the experimental period. Following thoracic caval constriction alone, aldosterone secretion increased within 30 minutes and reached levels two- to fourfold greater than the average control rates of 0.008 to $0.024 \mu \mathrm{g}$. per minute; corticosterone and Porter-Silber steroid output remained unchanged or decreased. Plasma volume was reduced. However, similar increases in aldosterone secretion occurred despite increased vascular volume secondary to infused dextran in three other animals with thoracic caval constriction. Two of four dogs with abdominal caval constriction showed increased aldosterone secretion; this occurred only after marked caval constriction and large sustained increments in venous pressure. The data demonstrate increased aldosterone secretion following acute constriction of the inferior vena cava above or below the hepatic veins and irrespective of changes in vascular volume.

\section{REFERENCES}

1. Davis, J. O., Pechet, M. M., Ball, W. C., Jr., and Goodkind, M. J. Increased aldosterone secretion in dogs with right-sided congestive heart failure and in dogs with thoracic inferior vena cava constriction. J. clin. Invest. 1957, 36, 689.

2. Davis, J. O., Goodkind, M. J., Pechet, M. M., and Ball, W. C., Jr. Increased excretion of aldosterone in urine from dogs with right-sided congestive heart failure and from dogs with thoracic inferior vena cava constriction. Amer. J. Physiol. 1956, 187, 45.

3. Kliman, B., and Peterson, R. E. Isotope derivative assay of aldosterone in biological extracts (abstract). Fed. Proc. 1958, 17, 255.

4. Peterson, R. E., Karrer, A., and Guerra, S. L. Evaluation of Silber-Porter procedure for determination of plasma hydrocortisone. Analyt. Chem. 1957, 29, 144.
5. Silber, R. H., and Porter, C. C. The determination of 17, 21-dihydroxy-20-ketosteroids in urine and plasma. J. biol. Chem. 1954, 210, 923.

6. Peterson, R. E. Unpublished observations.

7. Evelyn, K. A. A stabilized photoelectric colorimeter with light filters. J. biol. Chem. 1936, 115, 63.

8. Bowman, R. L., Trantham, H. V., and Caulfield, P. A. An instrument and method for rapid, dependable determination of freezing-point depression. J. Lab. clin. Med. 1954, 43, 310.

9. Ball, W. C., Jr., and Davis, J. O. Failure of chronic adrenal venous congestion to produce sodium retention and increased aldosterone excretion in the dog. Amer. J. Physiol. 1957, 191, 339.

10. Singer, B. Aldosterone in the adrenal vein blood of nephrotic rats. Endocrinology 1957, 60, 420.

11. Hamilton, C. E., Brown, W. J., Jr., and Hague, E. E. Comparison of adrenal morphology in dogs under dietary and circulatory handicap (abstract). Amer. J. Physiol. 1956, 187, 603.

12. Deane, H. W., and Barger, A. C. Histophysiology of the adrenal cortex in dogs with mild and severe cardiac damage. Endocrinology 1957, 61, 758.

13. Driscol, T. E., Maultsby, M. M., Farrell, G. L., and Berne, R. M. Aldosterone secretion in experimental congestive heart failure. Amer. J. Physiol. 1957, 191, 140.

14. Farrell, G. L., Rosnagle, R. S., and Rauschkolb, E. W. Increased aldosterone secretion in response to blood loss. Circulat. Res. 1956, 4, 606.

15. Epstein, F. H. Renal excretion of sodium and the concept of a volume receptor. Yale J. Biol. Med. 1956, 29, 282.

16. Farber, S. J., Becker, W. H., and Eichna, L. W. Electrolyte and water excretions and renal hemodynamics during induced congestion of the superior and inferior vena cava of man. J. clin. Invest. 1953, 32, 1145.

17. Ball, W. C., Jr., Davis, J. O., and Goodkind, M. J. Ascites formation without sodium intake in dogs with thoracic inferior vena cava constriction and in dogs with right-sided congestive heart failure. Amer. J. Physiol. 1957, 188, 578.

18. Davis, J. O., Howell, D. S., and Southworth, J. L. Mechanisms of fluid and electrolyte retention in experimental preparations in dogs. Circulat. Res. 1953, 1, 260.

19. Davis, J. O., Howell, D. S., and Hyatt, R. E. Sodium excretion in adrenalectomized dogs with chronic cardiac failure produced by pulmonary artery constriction. Amer. J. Physiol. 1955, 183, 263.

20. Liddle, G. W., Cornfield, J., Casper, A. G. T., and Bartter, F. C. The physiological basis for a method of assaying aldosterone in extracts of human urine. J. clin. Invest. 1955, 34, 1410. 
21. Luetscher, J. A., Jr., and Johnson, B. B. Observations on the sodium-retaining corticoid (aldosterone) in the urine of children and adults in relation to sodium balance and edema. J. clin. Invest. 1954, 33, 1441.

22. Davis, J. O., and Howell, D. S. Comparative effects of ACTH, cortisone and DCA on renal function, electrolyte excretion and water exchange in normal dogs. Endocrinology 1953, 52, 245.

23. Gaudino, M., and Levitt, M. F. Influence of the adrenal cortex on body water distribution and renal function. J. clin. Invest. 1949, 28, 1487.

24. Davis, J. O., Goodkind, M. J., and Ball, W. C., Jr. Functional changes during high output failure produced by daily hemorrhage in dogs with pulmonic stenosis. Circulat. Res. 1957, 5, 388.

25. Davis, J. O., and Howell, D. S. Mechanisms of fluid and electrolyte retention in experimental preparations in dogs. II. With thoracic inferior vena cava constriction. Circulat. Res. 1953, 1, 171.

26. Davis, J. O., Hyatt, R. E., and Howell, D. S. Right-sided congestive heart failure in dogs pro- duced by controlled progressive constriction of the pulmonary artery. Circulat. Res. 1955, 3, 252.

27. Johnson, R. D., and Conn, J. W. Aldosterone, antidiuretic hormone and congestive heart failure. Mod. Conc. cardiov. Dis. 1958, 27, 431.

28. Davis, J. O., and Ball, W. C., Jr. Effects of a body cast on aldosterone and sodium excretion in dogs with experimental ascites. Amer. J. Physiol. 1958, 192, 538.

29. Bartter, F. C. Aldosterone. Geneva Symposium, June, 1957. London, J. and A. Churchill, 1957.

30. Eisenberg, S. The effect of congestive heart failure on blood volume as determined by radio-chromiumtagged red cells. Circulation 1954, 10, 902.

31. Funkhouser, R. K., Pritchard, W. H., and Littell, A. S. Changes in relationship of blood volume to weight in congestive heart failure. Circulation 1957, 16, 548.

32. Eisenberg, S. The blood volume in patients with Laennec's cirrhosis as determined by radio-chromium-tagged red cells. Clin. Res. Proc. 1955, 3, 143. 